\title{
Calculating diabetic foot ulceration healing times using the Texas wound classification system
}

\author{
Jacqueline Forss ${ }^{*}$, David Till \\ From The College of Podiatry Annual Conference 2013: meeting abstracts \\ Liverpool, UK. 14-16 November 2013
}

\section{Background}

Healing rates of foot ulcers are unknown with the exception of specialist centres where it is between $80-90 \%$. The aim of this study was to ascertain average healing rates for people with diabetic foot ulceration attending a Multidisciplinary Diabetic Foot Team (MDFT) clinic by implementing the University of Texas wound classification system into clinical practice.

\section{Methods}

All patients presenting to the MDFT with active ulceration during 2010 had their ulcer classified using the Texas system and were entered into the audit. These ulcers were then monitored until healing or until the end of the data collection period (December 2012). A patient with multiple ulcer sites had each ulcer monitored separately. The average healing rates could then be calculated and compared.

\section{Results}

90 patients with ulcers were included with a total of 146 ulcers monitored. 32 ulcers were excluded as patients had either moved away, died, refused treatment, or withdrawn from the study due to non-concordance with treatment. 109 of the remaining 114 ulcers had healed by the end of the audit period (95.6\%)

The average healing rates were:

- Overall $=16.08$ weeks (range 1-74)

- Texas classification $\mathrm{A}=10.45$ weeks (range 2-20)

- Texas classification $B=12.12$ weeks (range 3-30)

- Texas classification $C=14.2$ weeks (range 1-42)

- Texas classification $\mathrm{D}=28.4$ weeks (range 4-74)
In relation to amputation rates:

- Texas classification $\mathrm{A}=0$

- Texas classification $\mathrm{B}=1$ minor

- Texas Classification $C=2$ minor

- Texas classification D $=3$ minor and 2 major amputations.

\section{Conclusion}

The Texas classification system was easy to use in clinical practice. The data demonstrates that average healing time varied according to the ulcer classification at presentation. To our knowledge, this has not previously been investigated. In addition, overall healing rates are higher than previously published data suggests, whereas amputation rates are similar to those reported using this classification system. It is recommended that the audit be continued to increase the sample sizes to identify any intergroup variation in mean healing times.

Published: 14 November 2014

\section{References}

1. Armstrong DG, Lavery LA, Harkless LB: Validation of a diabetic wound classification system. Diabetes Care 1998, 21:855-859.

2. Apelqvist J, Larsson J: What is the most effective way to reduce incidence of amputation in the diabetic foot? Diabetes/metabolism research and reviews 2000, 16:575-s83.

doi:10.1186/1757-1146-7-S2-A3

Cite this article as: Forss and Till: Calculating diabetic foot ulceration healing times using the Texas wound classification system. Journal of Foot and Ankle Research 2014 7(Suppl 2):A3.

East Sussex Healthcare Trust, East Sussex, UK 